\begin{tabular}{|c|c|}
\hline \multirow[t]{3}{*}{ Citation } & $\begin{array}{l}\text { Authors } \\
\text { Veryser Cedrick, Demaerel Joachim, Bieliūnas Vidmantas, Gilles Philippe, De Borg } \\
\text { graeve Wim }\end{array}$ \\
\hline & $\begin{array}{l}2018 \\
\text { Ex Situ Generation of Sulfuryl Fluoride for the Synthesis of Aryl Fluorosulf } \\
\text { ates }\end{array}$ \\
\hline & 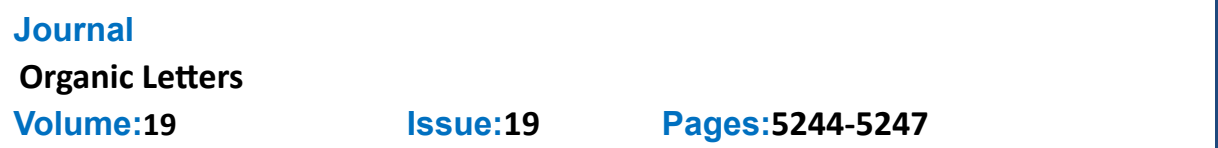 \\
\hline Archived version & (Manuscript before formatting by journal \\
\hline Published version & http://dx.doi.org/110.1021/acs.orglett.7b02522 \\
\hline Journal homepage & http://pubs.acs.org/journal/orlef7 \\
\hline Author contact & $\begin{array}{l}\text { wim.deborggraeve@kuleuven.be } \\
\text { +32 (0)16 } 327693\end{array}$ \\
\hline LIRIAS & https://lirias.kuleuven.be/handle/123456789/599322 \\
\hline
\end{tabular}

(article begins on next page) 


\title{
Ex Situ Generation of Sulfuryl Fluoride for the Synthesis of Aryl Fluorosulfates
}

\author{
Cedrick Veryser, ${ }^{\ddagger}$ Joachim Demaerel, ${ }^{\ddagger}$ Vidmantas Bieliūnas, Philippe Gilles, \\ and Wim M. De Borggraeve*(1)
}

Molecular Design and Synthesis, Department of Chemistry, KU Leuven, Celestijnenlaan 200F, Box 2404, 3001 Leuven, Belgium

Supporting Information

ABSTRACT: A convenient transformation of phenols into the corresponding aryl fluorosulfates is presented: the first protocol to completely circumvent direct handling of gaseous sulfuryl fluoride $\left(\mathrm{SO}_{2} \mathrm{~F}_{2}\right)$. The proposed method employs $1,1^{\prime}$-sulfonyldiimidazole as a precursor to generate near-stoichiometric amounts of $\mathrm{SO}_{2} \mathrm{~F}_{2}$ gas using a two-chamber reactor. With NMR studies, it was shown that this ex situ gas evolution is extremely rapid, and a variety of phenols and hydroxylated heteroarenes were fluorosulfated in good to excellent yields.

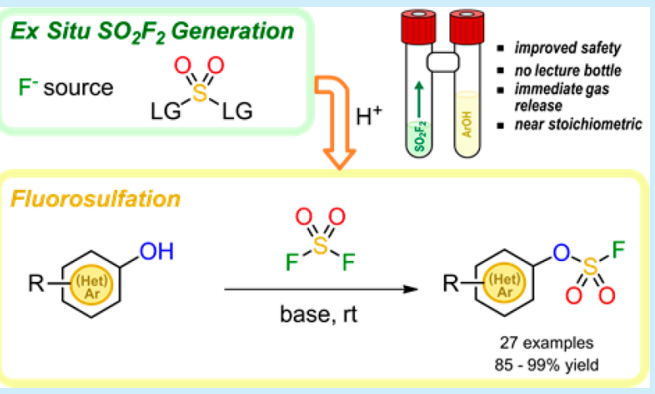

ince 2014, aryl fluorosulfates have sparked enormous $\checkmark$ interest as they give access to a broad and powerful set of applications. This is primarily due to the specific reactivity of the fluorosulfate group.

First, the S(VI)-F bond conveys onto the sulfur center an electrophilic behavior very different from other sulfonyl halides. Owing to these unique properties, the fluorosulfate moiety is inert toward most nucleophiles but reacts cleanly with either amines (by merit of protons solvating $\mathrm{F}^{-}$) or aryl silyl ethers (metathesizing into a diaryl sulfate and an extremely strong $\mathrm{Si}-$ F bond). This set of Lewis base mediated "click" reactions was recently disclosed by Sharpless and co-workers and baptized as sulfur(VI) fluoride exchange (SuFEx) chemistry. ${ }^{1}$ The SuFEx click reaction between aromatic bis(fluorosulfates) and bis(silyl ethers) can, for example, be applied for the synthesis of poly(aryl sulfates), sulfate-backboned analogs to polycarbonates which show promising mechanical properties. ${ }^{2}$ SuFEx chemistry has also found intriguing applications in selective and orthogonal postpolymerization modifications ${ }^{3}$ as well as in biomolecular and peptide chemistry. ${ }^{4}$

Second, besides being a robust connector handle, fluorosulfates are also excellent pseudohalides in transition-metalcatalyzed cross coupling reactions. Many applications have followed, including Suzuki-Miyaura, ${ }^{5}$ Negishi, ${ }^{6}$ or StilleMigita coupling, , $^{7}$ alkoxycarbonylation, ${ }^{8}$ and BuchwaldHartwig amination. ${ }^{9}$ Consequently, they are often considered as efficient triflate surrogates, albeit at a much lower production cost. Furthermore, aryl fluorosulfates are also versatile intermediates as they can be converted into aryl fluorides, ${ }^{10}$ aryl sulfamate esters, ${ }^{11}$ and others ${ }^{12}$ or can even be used for the synthesis of anhydrous tetraalkylammonium fluoride salts. ${ }^{13}$

Historically, aryl fluorosulfates are mainly synthesized via four different approaches. ${ }^{14}$ The first method relies on the pyrolysis of arenediazonium fluorosulfate salts. ${ }^{15}$ In the other three strategies, the appropriate phenol (or phenolate) is combined with fluorosulfonic anhydride, ${ }^{5 a, 6-8,16}$ sulfuryl chloride fluoride, ${ }^{17}$ or sulfuryl fluoride ${ }^{18}$ in the presence of a base at low temperature. Unfortunately, these approaches either require highly toxic and/or expensive reagents or make use of complicated and nonreliable reaction procedures (e.g., gas condensation) which often results in low yields.

Recently, Sharpless and others described a robust, reliable, and easy-to-execute synthesis of aryl fluorosulfates. ${ }^{1,2,19}$ These compounds were prepared from phenols and sulfuryl fluoride in the presence of a base, typically triethylamine. This finding has been foundational for the renewed interest in the fluorosulfate chemistry, considering that all newly discovered applications make use of this methodology.

The $\mathrm{SO}_{2} \mathrm{~F}_{2}$ gas is generally introduced using a balloon, filled from a pressurized lecture bottle. Other methods rely on the use of a stock solution of sulfuryl fluoride. ${ }^{10}$ Although sulfuryl fluoride gas is produced on an industrial scale and widely used as a fumigant, its impact on human health and the environment should not be neglected. ${ }^{20}$ The time-weighted average exposure limit for sulfuryl fluoride has been set at $5 \mathrm{ppm}$ by the Occupational Safety and Health Administration, indicating that long-term exposure is harmful for human well-being. ${ }^{20,21}$ The gas was also recently identified as a greenhouse gas with a global warming potential of 4800 relative to carbon dioxide and an atmospheric lifetime of 36 years. $^{22}$ Moreover, the limited number of suppliers makes it challenging and expensive to obtain a gas cylinder, especially when taking into account the costs of transportation and disposal. Despite the inherent drawbacks of this reagent, all reported procedures make (in)direct use of pressurized sulfuryl fluoride gas bottles and

Received: August 15, 2017 
thus are always associated with high cost and risks of explosion and leakage.

In summary, there is an urgent need to further develop new, convenient, and inherently safe methodologies to produce fluorosulfates, preferably starting from inexpensive and readily available commodity chemicals. Here, we report the first procedure for the on-demand ex situ generation of sulfuryl fluoride from a solid precursor for the synthesis of aryl fluorosulfates.

Our investigation began by scanning literature to identify potential sulfuryl fluoride precursors or surrogates. Inspired by the report of Prakash, sulfuryl chloride fluoride was selected as our first candidate. ${ }^{23}$ Therein, the $\mathrm{SO}_{2} \mathrm{ClF}$ gas could selectively be formed from sulfuryl chloride and a fluoride source in acidic medium and subsequently be isolated after gas condensation, albeit in low yield. We assumed that translating this work to a two-chamber reactor ${ }^{24}$ would significantly improve this method, as the generated gas can migrate to an adjacent chamber, where it is directly consumed thus avoiding intermediate isolation. This reactor was originally designed and commercialized by the Skrydstrup group. ${ }^{25}$ We have recently used this setup for the ex situ generation of carbon monoxide and sulfur dioxide for applications in organic synthesis. $^{26}$

After an extensive optimization study (see Supporting Information (SI)), the model substrate 4-fluoro-4'-hydroxybiphenyl was successfully converted into its corresponding aryl fluorosulfate 1 and isolated in $95 \%$ yield. Unfortunately, under the optimized reaction conditions (4 equiv of $\mathrm{SO}_{2} \mathrm{Cl}_{2}$ and 6 equiv of $\mathrm{KF}$ in $0.6 \mathrm{~mL}$ of $\mathrm{HCOOH}$ ) the transformation of the electron-rich 4-hydroxyanisole resulted in multiple chlorinated byproducts. Considering sulfuryl chloride's known behavior as a chlorinating agent in electrophilic aromatic substitutions, we speculate that the volatile $\mathrm{SO}_{2} \mathrm{Cl}_{2}$ and/or the $\mathrm{SO}_{2} \mathrm{ClF}$ also participate in this type of reaction. A similar observation was reported when sulfuryl chloride was used for the synthesis of aryl chlorosulfates. ${ }^{18 a}$

In order to eliminate the formation of chlorinated byproducts, we started looking for alternative nonvolatile precursors not containing chloride. In this respect, 1,1'sulfonyldiimidazole (SDI) seemed an attractive sulfuryl fluoride precursor, as it is a commercially available solid. It can also easily be synthesized and isolated by precipitation on gram scale from sulfuryl chloride and imidazole (see SI). As shown before, acidic conditions turn the imidazolium substituent into an excellent leaving group, ${ }^{27}$ and it was postulated that a 2 -fold displacement by fluoride would generate pure $\mathrm{SO}_{2} \mathrm{~F}_{2}$ gas.

First, SDI was evaluated under the previously optimized reaction conditions. Gratifyingly, full conversion toward the desired fluorosulfate 1 was observed after $18 \mathrm{~h}$ (Table 1, entry 1). Next, the reaction conditions were further modified to minimize the required amount of precursor. In formic acid, the number of equivalents of SDI could be reduced to 3.0, without affecting the conversion (entry 2). Further decreasing the amount of SDI resulted in incomplete conversion (entry 3). Minor improvements were achieved when the amount of potassium fluoride was increased or when the reaction was performed at $40{ }^{\circ} \mathrm{C}$ (entries 4-5). However, when formic acid was replaced by trifluoroacetic acid, the number of equivalents of SDI and KF could be significantly reduced to 1.5 and 4.0, respectively. These conditions furnished fluorosulfate $\mathbf{1}$ in an isolated yield of 96\% (entries 6-9). Again, product formation was hampered when the amount of SDI and/or KF were
Table 1. Optimization of Reaction Conditions ${ }^{a}$

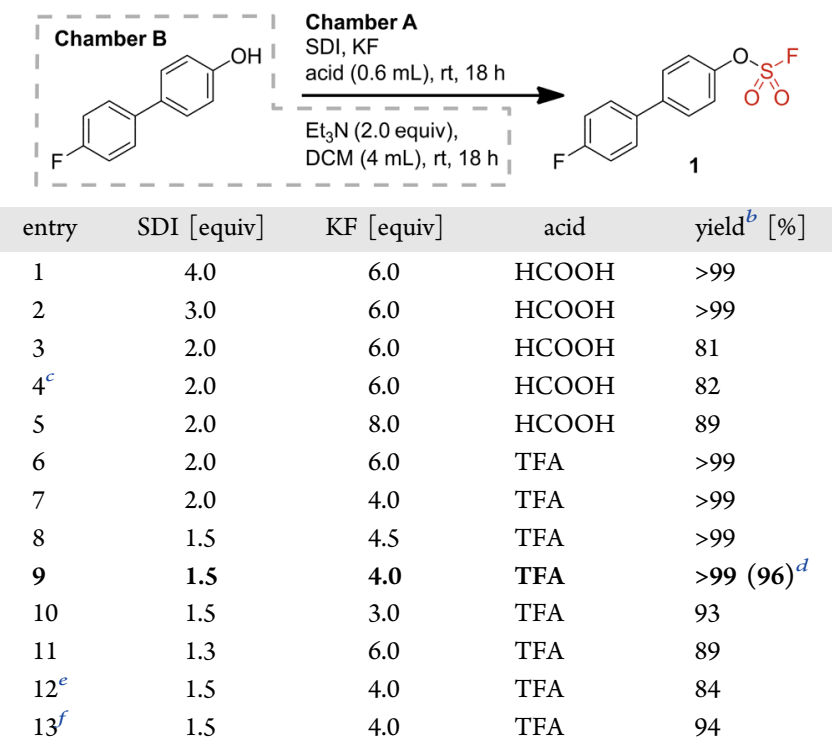

${ }^{a}$ Reaction conditions: Chamber A: 1,1'-sulfonyldiimidazole (SDI, 1.5 equiv), KF (4.0 equiv), and trifluoroacetic acid (TFA, $0.6 \mathrm{~mL}$ ) at rt for 18 h. Chamber B: 4-fluoro-4'-hydroxybiphenyl ( $0.5 \mathrm{mmol}), \mathrm{Et}_{3} \mathrm{~N}(2.0$ equiv) in dichloromethane $(4 \mathrm{~mL})$ at $\mathrm{rt}$ for $18 \mathrm{~h} .{ }^{b}$ Determined by ${ }^{19} \mathrm{~F}$ NMR using trifluorotoluene as internal standard. ${ }^{c}$ Chamber A was heated to $40{ }^{\circ} \mathrm{C}$. ${ }^{d}$ Isolated yield. ${ }^{e}$ Reaction run for 2 h. ${ }^{f}$ Reaction run for $8 \mathrm{~h}$.

further decreased (entries 10-11). The optimization study was finalized by investigating the influence of the reaction duration. After 2 and 6 h, the yield was $84 \%$ and 94\%, respectively (entries 12-13). We hypothesize that fluorosulfation is the rate-limiting step instead of the $\mathrm{SO}_{2} \mathrm{~F}_{2}$ generation from SDI. ${ }^{13} \mathrm{C}$ NMR confirmed that SDI completely decomposed in less than $30 \mathrm{~s}$ under the optimized reaction conditions (see SI). It was also shown that under these circumstances, the actual pressure inside the vessel remained well under the maximally allowed internal pressure (see SI).

With the optimized conditions in hand, we first tried to convert 4-hydroxyanisole into its corresponding aryl fluorosulfate $\mathbf{2}$ as this transformation was unsuccessful with sulfuryl chloride as a precursor. To our delight, the starting material was fully consumed under these reaction conditions and yielded the desired aryl fluorosulfate $\mathbf{2}$ in $91 \%$ isolated yield (Scheme 1). This clearly showed the usefulness of $1,1^{\prime}$-sulfonyldiimidazole as a sulfuryl fluoride precursor, as no byproducts were formed. In order to further explore the scope of this methodology, a broad and diverse set of phenol derivates was investigated (Scheme 1). First, monosubstituted electron-rich and -deficient phenols were successfully converted into their corresponding aryl fluorosulfates (3-11). These results illustrate that the electronic properties of the phenol derivates do not significantly influence the fluorosulfation reaction. Even sterically hindered aryl fluorosulfates were furnished in excellent yields $(9,10,11$, and 15). Also, naturally occurring phenols, such as eugenol, vanillin, and raspberry ketone turned out to be suitable substrates for this transformation $(12,13$, and 14), while $\mathrm{D}-\alpha$ tocopherol and $\beta$-estradiol produced only moderate conversion under the optimized reaction conditions. Gratifyingly, when the triethylamine dichloromethane system was substituted by $N, N$ diisopropylethylamine (DIPEA) in acetonitrile, ${ }^{28}$ the corresponding aryl fluorosulfates were acquired in near-quantitative 
Scheme 1. Synthesis of Aryl Fluorosulfates through ex Situ Generation of Sulfuryl Fluoride in a Two-Chamber Reactor ${ }^{a}$

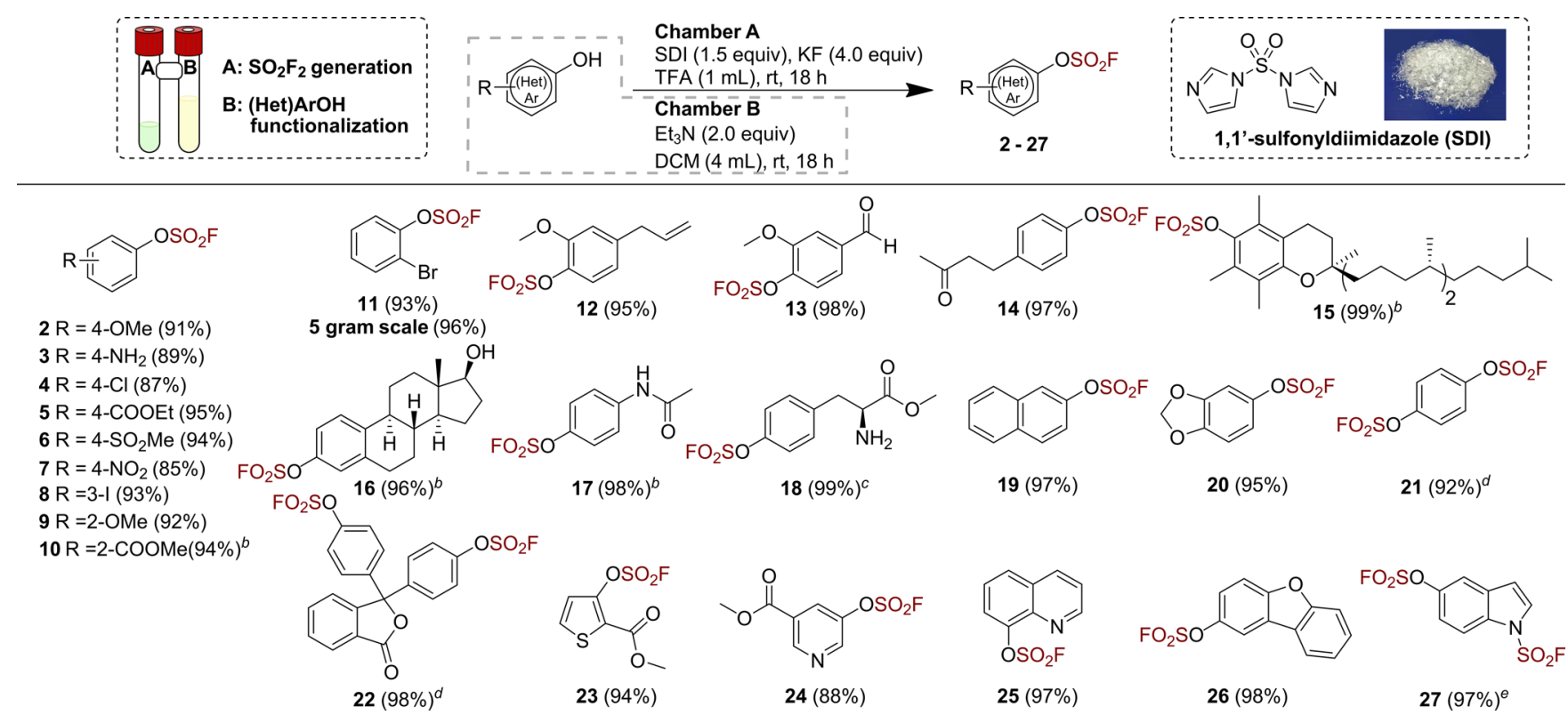

${ }^{a}$ Reaction conditions: Chamber A: $1,1^{\prime}$-sulfonyldiimidazole (1.5 equiv), KF (4.0 equiv) in TFA. Chamber B: (hetero)aryl alcohol (1.0 mmol), Et ${ }_{3} \mathrm{~N}$ (2.0 equiv) in DCM. Reaction details and pressure profile: see SI and instructional video. ${ }^{b}$ Chamber B: DIPEA (3.0 equiv) in MeCN. ${ }^{c}$ Chamber B: DIPEA (4.0 equiv) in MeCN. ${ }^{d}$ Chamber B: (hetero)aryl alcohol $(0.5 \mathrm{mmol}), \mathrm{Et}_{3} \mathrm{~N}$ (4.0 equiv) in DCM. ${ }^{e}$ Chamber B: (hetero)aryl alcohol (0.5 mmol), DIPEA (6.0 equiv) in $\mathrm{MeCN}$.

yields (15 and 16). These slightly modified conditions were also required for the fluorosulfation of paracetamol and Ltyrosine methyl ester (17 and 18). Next, two bicyclic phenol derivates were successfully tested (19 and 20). For the reaction of hydroquinone and phenolphthalein, 3.0 equiv of SDI and 4.0 equiv of triethylamine were added, resulting in the exclusive formation of the corresponding bis(fluorosulfates) (21 and 22). The scope was finalized by the synthesis of five heteroaryl fluorosulfates (23-27). It is worth noting that, under the applied reaction conditions, anilines, aliphatic alcohols, and aliphatic amines were tolerated, as only aromatic hydroxyl groups reacted with sulfuryl fluoride $(3,16$, and 18). This observation is in agreement with the results reported by the Sharpless group. ${ }^{1}$

The developed method is easily scaled up by simply using a larger two-chamber reactor. This was illustrated by synthesizing compound 11 on 5 gram scale. After an aqueous acid/base wash, the desired aryl fluorosulfate was achieved in 96\% yield (see $\mathrm{SI}$ ).

In conclusion, we have demonstrated a new, practical, and efficient way of transforming phenols into their corresponding aryl fluorosulfates in good to excellent yields. The proposed method relies on ex situ generation of sulfuryl fluoride gas from cheap and readily available commodity chemicals in a twochamber reactor. This provides a convenient means of transforming common phenolic substances, including some drug-like and naturally occurring compounds, into reactive aromatic intermediates. Furthermore, it is easily scaled up as evidenced by the preparation of analytically pure 2bromophenyl fluorosulfate on multigram scale using only extractive workup as the purification step. Further implementation of this promising chemistry within the larger research community can herewith be accelerated, where otherwise it might remain less explored due to the cumbersome handling of gaseous reagents. We speculate that the demand for these electrophilic functional handles will increase as they find their way into many more applications, by merit of their leaving group ability or as SuFEx partners.

\section{ASSOCIATED CONTENT}

\section{Supporting Information}

The Supporting Information is available free of charge on the ACS Publications website at DOI: 10.1021/acs.orglett.7b02522.

Experimental procedures, characterization for all compounds, decomposition study, and pressure profile (PDF)

Instructional video (AVI)

\section{AUTHOR INFORMATION}

\section{Corresponding Author}

*E-mail: wim.deborggraeve@kuleuven.be.

ORCID 우

Cedrick Veryser: 0000-0001-9076-3623

Wim M. De Borggraeve: 0000-0001-7813-6192

Author Contributions

$\ddagger$ C.V. and J.D. contributed equally.

Notes

The authors declare no competing financial interest.

\section{ACKNOWLEDGMENTS}

We are grateful to Karel Duerinckx (KU Leuven) for the assistance with NMR measurements and to Dirk Henot (KU Leuven) for the elemental analysis. C.V., J.D., and P.G. thank FWO (PhD Fellowship of the Research Foundation - Flanders) for fellowships received. W.M.D.B. thanks KU Leuven for financial support via Project OT/14/067. The Hercules 
Foundation is acknowledged for supporting the purchase of a $400 \mathrm{MHz}$ NMR spectrometer through project AKUL1311. V.B. and W.M.D.B. are grateful for funding received from the European Union's Horizon 2020 research and innovation program under the Marie Skłodowska-Curie grant agreement No. 721290.

\section{REFERENCES}

(1) Dong, J.; Krasnova, L.; Finn, M. G.; Sharpless, K. B. Angew. Chem., Int. Ed. 2014, 53, 9430-9448.

(2) (a) Dong, J.; Sharpless, K. B.; Kwisnek, L.; Oakdale, J. S.; Fokin, V. V. Angew. Chem., Int. Ed. 2014, 53, 9466-9470. (b) Gao, B.; Zhang, L.; Zheng, Q.; Zhou, F.; Klivansky, L. M.; Lu, J.; Liu, Y.; Dong, J.; Wu, P.; Sharpless, K. B. Nat. Chem. 2017, DOI: 10.1038/nchem.2796.

(3) (a) Oakdale, J. S.; Kwisnek, L.; Fokin, V. V. Macromolecules 2016, 49, 4473-4479. (b) Li, S.; Beringer, L. T.; Chen, S.; Averick, S. Polymer 2015, 78, 37-41.

(4) (a) Baranczak, A.; Liu, Y.; Connelly, S.; Du, W.-G. H.; Greiner, E. R.; Genereux, J. C.; Wiseman, R. L.; Eisele, Y. S.; Bradbury, N. C.; Dong, J.; Noodleman, L.; Sharpless, K. B.; Wilson, I. A.; Encalada, S. E.; Kelly, J. W. J. Am. Chem. Soc. 2015, 137, 7404-7414. (b) Chen, W.; Dong, J.; Li, S.; Liu, Y.; Wang, Y.; Yoon, L.; Wu, P.; Sharpless, K. B.; Kelly, J. W. Angew. Chem., Int. Ed. 2016, 55, 1835-1838. (c) Chen, W.; Dong, J.; Plate, L.; Mortenson, D. E.; Brighty, G. J.; Li, S.; Liu, Y.; Galmozzi, A.; Lee, P. S.; Hulce, J. J.; Cravatt, B. F.; Saez, E.; Powers, E. T.; Wilson, I. A.; Sharpless, K. B.; Kelly, J. W. J. Am. Chem. Soc. 2016, 138, 7353-7364. (d) Yatvin, J.; Brooks, K.; Locklin, J. Angew. Chem., Int. Ed. 2015, 54, 13370-13373.

(5) (a) Clark, W. M.; Tickner-Eldridge, A. M.; Huang, G. K.; Pridgen, L. N.; Olsen, M. A.; Mills, R. J.; Lantos, I.; Baine, N. H. J. Am. Chem. Soc. 1998, 120, 4550-4551. (b) Pridgen, L. N.; Huang, G. K. Tetrahedron Lett. 1998, 39, 8421-8424. (c) Hanley, P. S.; Ober, M. S.; Krasovskiy, A. L.; Whiteker, G. T.; Kruper, W. J. ACS Catal. 2015, 5, 5041-5046. (d) Liang, Q.; Xing, P.; Huang, Z.; Dong, J.; Sharpless, K. B.; Li, X.; Jiang, B. Org. Lett. 2015, 17, 1942-1945. (e) Zhang, E.; Tang, J.; Li, S.; Wu, P.; Moses, J. E.; Sharpless, K. B. Chem. - Eur. J. 2016, 22, 5692-5697.

(6) Roth, G. P.; Fuller, C. E. J. Org. Chem. 1991, 56, 3493-3496.

(7) Roth, G. P.; Sapino, C. Tetrahedron Lett. 1991, 32, 4073-4076.

(8) (a) Roth, G. P.; Thomas, J. A. Tetrahedron Lett. 1992, 33, 19591962. (b) McGuire, M. A.; Sorenson, E.; Owings, F. W.; Resnick, T. M.; Fox, M.; Baine, N. H. J. Org. Chem. 1994, 59, 6683-6686. (c) Fang, W.-Y.; Leng, J.; Qin, H.-L. Chem. - Asian J. 2017, 12, 23232331.

(9) (a) Hanley, P. S.; Clark, T. P.; Krasovskiy, A. L.; Ober, M. S.; O'Brien, J. P.; Staton, T. S. ACS Catal. 2016, 6, 3515-3519. (b) Lim, T.; Byun, S.; Kim, B. M. Asian J. Org. Chem. 2017, DOI: 10.1002/ ajoc.201700064.

(10) Schimler, S. D.; Cismesia, M. A.; Hanley, P. S.; Froese, R. D. J.; Jansma, M. J.; Bland, D. C.; Sanford, M. S. J. Am. Chem. Soc. 2017, 139, $1452-1455$.

(11) Ren, G.; Zheng, Q.; Wang, H. Org. Lett. 2017, 19, 1582-1585.

(12) (a) Chen, Q.; Yu, H.; Xu, Z.; Lin, L.; Jiang, X.; Wang, R. J. Org. Chem. 2015, 80, 6890-6896. (b) Wang, X.-Y.; Leng, J.; Wang, S.-M.; Asiri, A. M.; Marwani, H. M.; Qin, H.-L. Tetrahedron Lett. 2017, 58, 2340-2343.

(13) Cismesia, M. A.; Ryan, S. J.; Bland, D. C.; Sanford, M. S. J. Org.

Chem. 2017, 82, 5020-5026.

(14) Stang, P. J.; Hanack, M.; Subramanian, L. R. Synthesis 1982, $1982,85-126$.

(15) Lange, W.; Müller, E. Ber. Dtsch. Chem. Ges. B 1930, 63, 26532657.

(16) Boudakian, M. M.; Hyde, G. A.; Kongpricha, S. J. Org. Chem. 1971, 36, 940-942.

(17) Cramer, R; Coffman, D. J. Org. Chem. 1961, 26, 4164-4165.

(18) (a) Firth, W. C. J. Polym. Sci., Part B: Polym. Lett. 1972, 10, 637-641. (b) Hedayatullah, M.; Guy, A.; Denivelle, L. C. R. Acad. Sc. Paris 1974, 278, 57-59. (c) Falardeau, E. R.; DesMarteau, D. D. J.
Chem. Eng. Data 1976, 21, 386-387. (d) Hedayatullah, M.; Guy, A.; Denivelle, L. Phosphorus Sulfur Relat. Elem. 1980, 8, 125-126.

(19) (a) Ishii, A.; Yasumoto, M. Method for Producing Fluorosulfuric Acid Ester. US 2011/0201825A1, August 18, 2011. (b) Ishii, A.; Ishimaru, T.; Yamazaki, T.; Yasumoto, M. Process for Producing Fluorosulfuric Acid Aromatic-ring Esters. WO 2013/002040A1, January 3, 2013.

(20) Tsai, W.-T. J. Environ. Sci. Health C 2010, 28, 125-145.

(21) Schneir, A.; Clark, R. F.; Kene, M.; Betten, D. Clin. Toxicol. 2008, 46, 850-854.

(22) (a) Papadimitriou, V. C.; Portmann, R. W.; Fahey, D. W.; Mühle, J.; Weiss, R. F.; Burkholder, J. B. J. Phys. Chem. A 2008, 112, 12657-12666. (b) Mühle, J.; Huang, J.; Weiss, R. F.; Prinn, R. G.; Miller, B. R.; Salameh, P. K.; Harth, C. M.; Fraser, P. J.; Porter, L. W.; Greally, B. R.; O’Doherty, S.; Simmonds, P. G. J. Geophys. Res. Atmos. 2009, 114, D05306. (c) Nie, Y.; Zheng, Q.; Liang, X.; Gu, D.; Lu, M.; Min, M.; Ji, J. Environ. Sci. Technol. 2013, 47, 7934-7939.

(23) Prakash Reddy, V.; Bellew, D. R.; Prakash, G. K. S. J. Fluorine Chem. 1992, 56, 195-197.

(24) The two-chamber reactor is commercially available under the trade name COware at Sigma-Aldrich and Sytracks.

(25) (a) Hermange, P.; Lindhardt, A. T.; Taaning, R. H.; Bjerglund, K.; Lupp, D.; Skrydstrup, T. J. Am. Chem. Soc. 2011, 133, 6061-6071. (b) Friis, S. D.; Lindhardt, A. T.; Skrydstrup, T. Acc. Chem. Res. 2016, 49, 594-605.

(26) (a) Veryser, C.; Van Mileghem, S.; Egle, B.; Gilles, P.; De Borggraeve, W. M. React. Chem. Eng. 2016, 1, 142-146. (b) Van Mileghem, S.; De Borggraeve, W. M. Org. Process Res. Dev. 2017, 21, 785-787. (c) Veryser, C.; Steurs, G.; Van Meervelt, L.; De Borggraeve, W. M. Adv. Synth. Catal. 2017, 359, 1271-1276. (d) Van Mileghem, S.; Egle, B.; Gilles, P.; Veryser, C.; Van Meervelt, L.; De Borggraeve, W. M. Org. Biomol. Chem. 2017, 15, 373-378.

(27) (a) Chou, T. S.; Becke, L. M.; O’Toole, J. C.; Carr, M. A.; Parker, B. E. Tetrahedron Lett. 1996, 37, 17-20. (b) Uematsu, N.; Hoshi, N.; Ikeda, M. J. Fluorine Chem. 2006, 127, 1595-1600.

(28) These conditions were adopted from ref 5e. In each case tested, the combination of DIPEA/MeCN performed either equally well or better than $\mathrm{Et}_{3} \mathrm{~N} / \mathrm{DCM}$, in some cases presumably due to solubility. However, when this modification was not necessary, DCM was kept as solvent for its ease of evaporation. 